\title{
Sequence analysis of selected nucleotide sequences of abortogenic isolate of Equine Herpesvirus 1 and changes caused by serial passage in vitro
}

\author{
Dobromila Molinková \\ Institute of Epidemiology and Microbiology, University of Veterinary and Pharmaceutical Sciences Brno, \\ Czech Republic
}

Received October 27, 2011

Accepted February 14, 2012

\begin{abstract}
The aim of this work was to isolate the abortogenic virus strain of Equine Herpesvirus 1 representing the current infection situation in the Czech Republic, describe it at the molecular level with accent on genes coding viral glycoproteins and observe the changes caused by the passaging of the virus on a cell culture. In 2009, an isolate of equine herpesvirus 1 was obtained from an abortion case in a mare from a herd affected by abortion storm. The virus identification was performed using the PCR method. The virus was isolated on the RK 13 cell line and after 6 passages in vitro the stability of sequences of selected sections of the virus genome was assessed and compared with the original field isolate. The virus sequences were also compared with known sequences of the abortogenic reference virus strain (V592) and with other known viral strains. One point mutation in a nucleotide sequence coding glycoprotein $\mathrm{G}$ was found, distinguishing the field isolate from V592. One point mutation in the gene for glycoprotein $\mathrm{C}$ was passage-induced. It was noted that the virus during the passage on RK13 cell line in the monitored sections was stable and is a suitable starting material for next experiments.
\end{abstract}

EHV-1, viral abortion in mares, glycoproteins, genom

Up to now a total of five herpesviruses have been isolated in horses. Only three of them cause clinically significant disease. They are especially the Equine Herpesvirus 1, Equine Herpesvirus 3 and Equine Herpesvirus 4 (EHV-1, EHV-3 and EHV-4). Diseases caused by EHV-1 and EHV-4 have the greatest impacts on health. EHV-1 is currently known as the etiologic agent of herpesviral abortion in mares (Studdert et al. 1981).

In pregnant mares the EHV-1 infection may result in the abortion of the foetus (Studdert and Blackney 1979). Crucial to the clinical course of disease is the stage of gestation. Abortions which are due to EHV-1 infection occur during the last three months of pregnancy (Awan et al. 1995). The number of aborting mares in the herd cannot be predicted. The incidence varies from isolated cases up to $70 \%$.

The size of the EHV-1 genome is approximately 150,000 bp. The EHV-1 genome is composed of two subunits. The smaller subunit (unique short - $U_{s}$ ) is bounded by repeated stretches called "terminal repeats" $\left(\mathrm{TR}_{\mathrm{s}}\right)$ and "internal repeats" $\left(\mathrm{IR}_{\mathrm{s}}\right)$. The larger subunit (unique long $-\mathrm{U}_{1}$ ) is bounded by repeated stretches of $T R_{1}$ and $\mathrm{IR}_{1}$, which are smaller than the corresponding sequences of $U_{s}$ (Telford et al. 1998).

Viral glycoproteins play an important role in the disease pathogenesis. They are responsible for the virus pathogenicity (Manservigi and Cassai 1991) and the immune response of an infected organism is directed against them (Whalley et al. 1995). They are glycosylated proteins integrated into the virus lipid envelope. In total, 11 glycoproteins were identified in EHV-1, referred to as glycoprotein $\mathrm{B}(\mathrm{gB}), \mathrm{gC}, \mathrm{gD}, \mathrm{gE}, \mathrm{gG}, \mathrm{gH}, \mathrm{gI}, \mathrm{gJ}$, $\mathrm{gK}, \mathrm{gL}$ and $\mathrm{gM}$.

Surface glycoproteins are conserved within the Herpesviridae family to some extent. $\mathrm{gB}$ and $\mathrm{gH}$ are considered the most conserved glycoproteins. Glycoproteins $\mathrm{E}$ and I are conserved especially in neurotropic strains of herpesvirus (Frampton et al. 2004). 
Glycoproteins are divided into those that are essential for virus replication ( $\mathrm{gB}, \mathrm{gD}, \mathrm{gH} /$ $\mathrm{L}, \mathrm{gK}$ ) and those that are not (gC, gE, gI, gG, gM) (Cairns et al. 2003).

Due to the localization of viral glycoproteins on the virus particles surface they are molecules coming into direct contact with the host immune system. In essential glycoproteins, therefore, we encounter the presence of neutralizing epitopes.

The aim of the study was to describe the field isolate of highly abortogenic EHV-1 at the genome level, especially in genes that encode proteins essential for the immune response of the body, i.e. for viral glycoproteins. Nucleotide sequences observed in this study encode glycoproteins C, D, E, G and I. In the genome of EHV-1 they are located inside $\mathrm{U}_{1}\left(\mathrm{gC}\right.$ : CDS16), but mostly within the $\mathrm{U}_{\mathrm{s}}$ (gG: CDS70, gD: CDS72, gI: CDS73 and $\mathrm{gE}$ : CDS74). This virus was intended to isolate on the cell culture, and then test for the stability of the observed sequences after the $6^{\text {th }}$ passage. The obtained sequences were compared with the known abortogenic strain EHV-1 labelled V592 (GenBank AY464052), with a representative of attenuated strains of the virus Kentucky A (KyA) (GenBank S57839.1 for gC and M62923.1 for gD) and with a partial sequence for $\mathrm{gD}$ of isolate Lucina, obtained from the Czech Republic in 2003 (Molinkova et al. 2004).

\section{Materials and Methods}

Ten-percent suspension of liver and placental tissue of aborted foal in Hank's balanced salt solution was used for isolating the virus. The suspension was centrifuged for $10 \mathrm{~min}$ at $6,000 \mathrm{~g}$ and filtered through a $0.22 \mu \mathrm{m}$ filter (Sigma, USA). The material was stored at $-80^{\circ} \mathrm{C}$.

Cell line RK-13 (Rabbit kidney) was used for isolating the virus. Cells were cultured in Dulbecco's modified Eagle's medium with an addition of $10 \%$ bovine foetal serum to achieve a $70-80 \%$ monolayer. Then they were inoculated with the tested material. The daily emergence of cythopathic effect was monitored in the infected cell culture. When it reached $70 \%$, the culture was frozen at $-80^{\circ} \mathrm{C}$. The following passages of the virus were carried out repeatedly with deep-frozen and defrosted material.

Total DNA was extracted from an aborted foetus placental tissue using the NucleoSpin Tissue kit (MachereyNagel, Germany) following the manufacturer's instructions. DNA from the $6^{\text {th }}$ passage of the virus on RK13 was isolated using the Kit NucleoSpin Blood (Macherey-Nagel, Germany) following the manufacturer's instructions. The obtained DNA was labelled and stored at $-80^{\circ} \mathrm{C}$.

The presence of EHV-1 DNA was confirmed both in the material obtained directly from the aborted foal placenta as well as in the material from the $6^{\text {th }}$ passage of the obtained virus isolate on the RK13 cell line using the species-specific polymerase chain reaction (PCR) as described by Lawrence et al. (1994).

Selected sections of DNA designated for the monitoring of nucleotide sequences were amplified in $100 \mu$ PCR using reaction mixture Combi PPP MasterMix (TopBIO, Czech Republic) with the addition of appropriate pairs of oligonucleotide primers (Table 1). Reaction conditions: after $4 \mathrm{~min}$ at $94{ }^{\circ} \mathrm{C}$ of initial denaturation, 35 cycles followed: denaturation $\left(45 \mathrm{~s} / 94^{\circ} \mathrm{C}\right)$, annealing $\left(45 \mathrm{~s} / 52^{\circ} \mathrm{C}\right)$, extension $\left(1 \mathrm{~min} / 72^{\circ} \mathrm{C}\right)$.

Table 1. Sequence and position of primers used

\begin{tabular}{llr}
\hline & \multicolumn{1}{c}{ Sequence } & Position in V592 genome \\
\hline gE-r & AATACAGCCCCACACCACC & 135374 \\
gE-f & CATCAGAGCGACCAAGATCC & 134921 \\
gI-r & CGACCAGTAGAACATCTTCC & 133415 \\
gI-f & TTCGCGTAAAACTTGACC & 133014 \\
gC-1,4 & GAGACGGTAACGCTGGTACTGTTAA ${ }^{1}$ & 22200 \\
gC-4 & AGCCACGAACAACTCAACCGATGT & \\
gC-1 & GCGAGATGTGGTTGCCTAATCTCG & EHV-4 \\
gG-r & TTAAGCAACGTACTCAA & 22848 \\
gG-f & TTGACTGTCTTAGCA & 128391 \\
gD-r & TCCTTCTTCCGACGCAAGCA & 127159 \\
gD-f & CACCACCTTCAAGCTTATGATGGA & 132397 \\
\hline
\end{tabular}

${ }^{1}$ Lawrence et al. 1994 
The sequencing reaction took place in $20 \mu \mathrm{l}$ of reaction mixture composed of $2 \mu \mathrm{l}$ buffer, $2 \mu 12 \times$ concentrated sequencing mixture Big Dye Terminator v3.1 cycle Sequencing Kit (Applied Biosystems, USA), $3 \mu 1$ of DNA, $3.5 \mu \mathrm{l}$ of the appropriate primer $(10 \mathrm{pmol} / \mu \mathrm{l}), 9.5 \mu 1 \mathrm{H}_{2} \mathrm{O}$; in the following conditions: 30 cycles of denaturation $\left(20 \mathrm{~s} / 96^{\circ} \mathrm{C}\right)$, annealing $\left(20 \mathrm{~s} / 50{ }^{\circ} \mathrm{C}\right)$ and elongation $\left(4 \mathrm{~min} / 60{ }^{\circ} \mathrm{C}\right)$.

Data obtained through sequencing were processed and analysed using the Chromas Lite (Technelysium Pty Ltd., Austria) and Vektor NTI (Invitrogen, USA) software.

\section{Results}

In our study we isolated the abortogenic strain of EHV-1 which was named "Prostejov" after the location of the affected farm.

The total length of nucleotide sequences obtained both in the field isolate and in the virus obtained in the cell culture by passaging was $3045 \mathrm{bp}$. We obtained partial sequences of genes encoding glycoproteins C (GenBank JN39738), D (GenBank JN397384), E (GenBank JN397385), G (GenBank JN397386) and I (GenBank JN397387). The lengths of these sequences were: $511 \mathrm{bp}$ for $\mathrm{gC}, 1029$ for $\mathrm{gD}, 441$ for $\mathrm{gE}, 1118$ for $\mathrm{gG}$ and 387 for $\mathrm{gI}$.

Comparison of sequences of Prostejov field isolate demonstrated a high compliance with the reference abortogenic strain EHV-1 known as V592 (GenBank AY464052). In the monitored sections of DNA we found only one point mutation at position 127679 of the V592 genom. The change can be identified in the gene for glycoprotein G. While in the V592 genome there is guanine at this position, in Prostejov and even in the virus attenuated at the cell culture, adenine was found in this position. For the encoded sequence of amino acids this means a change from asparagine to aspartic acid (Fig. 1).

Fig. 1. Comparison of the sequences encoding part of glycoprotein G. Change of amino acid from D (aspartic acid) to N (asparagine) caused by point mutation distinguishing V592 from the Prostejov isolate and the passaged virus.

\begin{tabular}{|c|c|c|c|}
\hline \multicolumn{3}{|c|}{$\underline{\text { Nucleotide sequences } \mathrm{gG}}$} & \multirow{2}{*}{$\underline{\text { Aminoacid sequences }}$} \\
\hline & & 127666 & \\
\hline V592 AY464052 & (127666) & GAAGTGGAAAAG $\underline{\text { GACACAAACTAT }}$ & RVTLEVEKDTNYPCGMIH \\
\hline gG Prostejov & $(460)$ & GAAGTGGAAAAG $\underline{\text { AACACAAACTAT }}$ & RVTLEVEKNָTNYPCGMIH \\
\hline gG cell culture & (460) & GAAGTGGAAAAG $\underline{A} A C A C A A A C T A T$ & RVTLEVEKNTNNYPCGMIH \\
\hline
\end{tabular}

Comparison of sequences of attenuated virus with sequences of the original field isolate also showed a solid match. Only one point mutation was found again in position 22412 of the V592 genom, which occurred in the stretch encoding gC for a change of cytosine to thymine. For the amino acid sequence this means a change: glutamic acid - lysine (Fig. 2). When compared with sequences of the known Kentucky A strain (GenBank S57839) which was passaged in vitro many times (Colle et al. 1996), this mutation was found also in this representative of laboratory strains. However, our trial

Fig. 2. Comparison of the sequences encoding glycoprotein C. Changing the amino acid E (glutamic acid) to $\mathrm{K}$ (lysine) at the point mutation, resulting from the passaging of the Prostejov virus in the cell culture.

\begin{tabular}{|c|c|c|c|}
\hline \multicolumn{3}{|c|}{ Nucleotide sequences gC } & \multirow[t]{2}{*}{$\underline{\text { Aminoacid sequences }}$} \\
\hline & & 22400 & \\
\hline V592 AY464052 & $(22400)$ & TTTTTTCCTCTㅌTGCCGTTGAGA & LLLFSTAERKKSRRGGQL \\
\hline $\mathrm{gC}$ Prostejov & (113) & TTTTTTCCTCTㅡTGCCGTTGAGA & LLLFSTAERKKSRRGGQL \\
\hline $\mathrm{gC}$ cell culture & $(133)$ & TTTTTTCCTCTITTGCCGTTGAGA & LLLFSTA $\underline{\text { KRKKSRRGGQL }}$ \\
\hline gC Kentucky A & $(2183)$ & TTTTTTCCTCT⿻̄TTGCCGTTGAGA & \\
\hline
\end{tabular}


does not prove another difference between the V592 and KyA (position 22526) that occurs in the monitored section.

Other differences were found between the sequences of $\mathrm{gD}$ Prostejov and Lucina isolates. Both isolates come from the Czech Republic, but they were obtained at different times (Lucina in 2003, Prostejov in 2009). In these sequences the Prostejov isolate and the passaged virus correspond in 100\% with V592 sequences, but differ from Lucina in three loci. No passage-induced point mutations were found in $\mathrm{gD}$ sequences of our passaged virus in contrast to KyA (GenBank M62923.1) (data not shown).

The sequence of gene sections for $\mathrm{gE}$ and $\mathrm{gI}$ are fully consistent with the relevant sequences of the reference virus strain V592.

\section{Discussion}

Sections of the genome of the field isolate coding for the main surface glycoproteins of EHV-1 were selected for surveying the Prostejov field isolate and for determining the stability of the isolated virus during the passaging in the cell culture. These glycoproteins are crucial both for the properties of the virus during infection of host cells ( $\mathrm{gC}, \mathrm{gD}, \mathrm{gI}$ and gE [Damiani et al. 2000; Schimmer and Neubauer 2003; Spear and Longnecker 2003]) and for a specific immune reaction of the host organism ( $\mathrm{gC}, \mathrm{gD}$ and $\mathrm{gE} \mathrm{gI}$ [Manservigi and Cassai 1991; Damiani et al. 2000]). The gene for glycoprotein $G$ was observed due to the possible use in controlling post-vaccination antibody titres of species-specific serological ELISA test distinguishing the closely related EHV-4 (Crabb and Studdert 1993).

Prostejov isolate and the virus cultured in cell culture differed from the reference abortogenic strain V592 only in the sequence of the gene for $\mathrm{gG}$. This point mutation does not affect the species-specific immunogenic epitopes located in the $\mathrm{C}$-terminal part of glycoprotein $\mathrm{G}$ (Crabb and Studdert 1993). In other genome sections under observation the Prostejov isolate does not vary from the reference strain V592 which proves the conservation of the genome of the EHV-1 virus; similarly to the absolute match in the sequences of parts of genes for $\mathrm{gE}$ and $\mathrm{gI}$ (Ghanem et al. 2007).

In monitoring the stability of our isolate during the in vitro passage on cell line RK13 (6 passages) we discovered a single point mutation which differentiates the sequence of the passaged virus from the sequence of the field isolate in the section encoding $\mathrm{gC}$. This mutation occurs in the Kentucky A strain which was subjected to passage in heterologous hosts and in cell cultures (Colle et al. 1996). It appears that this is the locus of the virus genome passage prone to change. Unfortunately, we did not obtain the sequence encoding the main immunodominant epitopes of $\mathrm{gC}$ (Crabb and Studdert 1995). More work should be done in this field. Other changes that we could observe both in sequences $\mathrm{gC}$ and $\mathrm{gD}$ in Kentucky A did not occur in the sequences of passaged virus from our experiment.

It was interesting to compare the Prostejov isolate sequences with the other Czech isolate called Lucina obtained in 2003. Unfortunately, only a partial gene sequence for $\mathrm{gD}$ is available in this isolate. In the monitored $\mathrm{gD}$ section the sequences of both viruses differ in three loci. This may suggest the occurrence of an entirely different abortogenic strain in the Czech Republic in the span of six years.

Although the point mutation in the gene for a functional protein EHV-1 can mean, for example, an increase in the virus neuropathogenicity as was demonstrated in the gene for DNA polymerase (Nugent et al. 2006), we suspect that the nucleotide variation in the gene for glycoprotein $G$ in the Prostejov isolate observed in this work will not have any importance for the pathogenesis of the disease. Similarly, the mutation in the gene for $\mathrm{gC}$ in the passaged virus will not have any effect on the construction of key neutralizing epitopes of this virus. 


\section{Acknowledgements}

This work was supported by MZeČR NAZV QH 92265.

\section{References}

Awan AR, Baxi M, Field HJ 1995: EHV-1-induced abortion in mice and its relationship to stage of gestation. Res Vet Sci 59: 139-145

Cairns TM, Milne RS, Ponce-de-Leon M, Tobin DK, Cohen GH, Eisenberg RJ 2003: Structure-function analysis of herpes simplex virus type $1 \mathrm{gD}$ and $\mathrm{gH}-\mathrm{gL}$ : clues from $\mathrm{gDgH}$ chimeras. J Virol 77: 6731-6742

Colle CF 3rd, Tarbet EB, Grafton WD, Jennings SR, O`Callaghan DJ 1996: Equine herpesvirus-1 strain KyA, a candidate vaccine strain, reduces viral titers in mice challenged with a pathogenic strain, RacL. Virus Res 43: $111-124$

Crabb BS, Studdert MJ 1993: Epitopes of glycoprotein G of equine herpesviruses 4 and 1 located near the C termini elicit type-specific antibody responses in the natural host. J Virol 67: 6332-6338

Crabb BS, Studdert MJ 1995: Expression of small regions of equine herpesvirus 1 glycoprotein C in Escherichia coli. Vet Microbiol 46: 181-191

Damiani AM, Matsumura T, Jang HK, Izumiya Y, Mikami T, Takahashi E 2000: Identification of the products of the equine herpesvirus type 4 gI and gE genes. Arch Virol 145: 1489-1496

Frampton AR Jr, Smith PM, Zhang Y, Grafton WD, Matsumura T, Osterrieder N, O'Callaghan DJ 2004: Meningoencephalitis in mice infected with an equine herpesvirus 1 strain KyA recombinant expressing glycoprotein I and glycoprotein E. Virus Genes 29: 9-17

Ghanem YM, Ibrahim el-SM, Yamada S, Matsumura T, Osterrieder N, Yamaguchi T, Fukushi H 2007: Molecular characterization of the equine herpesvirus 1 strains RacL11 and Kentucky D. J Vet Med Sci 69: 573-576

Lawrence GL, Gilkerson J, Love DN, Sabine M, Whalley JM 1994: Rapid, single-step differentiation of equid herpesviruses 1 and 4 from clinical material using the polymerase chain reaction and virus-specific primers. J Virol Methods 47: 59-72

Manservigi R, Cassai E 1991: The glycoproteins of the human herpesviruses. Comp Immunol Microbiol Infect. Dis 14: 81-95

Molinková D, Celer V Jr, Jahn P 2004: Isolation and partial characterization of equine herpesvirus type 1 in Czechia. Folia Microbiol (Praha) 49: 605-611

Nugent J, Birch-Machin I, Smith KC, Mumford JA, Swann Z, Newton JR, Bowden RJ, Allen GP, Davis-Poynter N 2006: Analysis of equid herpesvirus 1 strain variation reveals a point mutation of the DNA polymerase strongly associated with neuropathogenic versus nonneuropathogenic disease outbreaks. J Virol 80: 4047-4060

Schimmer C, Neubauer A 2003: The equine herpesvirus 1 UL11 gene product localizes to the trans-golgi network and is involved in cell-to-cell spread. Virology 308: 23-36

Spear PG, Longnecker R 2003: Herpesvirus entry: an update. J Virol 77: 10179-10185

Studdert MJ, Blackney MH 1979: Equine herpesviruses: on the differentiation of respiratory from foetal strains of type 1. Aust Vet J 55: 488-492

Studdert MJ, Simpson T, Roizman B 1981: Differentiation of respiratory and abortigenic isolates of equine herpesvirus 1 by restriction endonucleases. Science 30: 562-564

Telford EA, Watson MS, Perry J, Cullinane AA, Davison AJ 1998: The DNA sequence of equine herpesvirus-4. J Gen Virol 79: 1197-1203

Whalley JM, Love DN, Tewari D, Field HJ 1995: Characteristics of equine herpesvirus 1 glycoproteins expressed in insect cells. Vet Microbiol 46: 193-201 